\title{
Phosphine Oxide Polymer For Water-Soluble Nanoparticles
}

\section{Supporting Information}

\author{
Sang-Wook Kim, Sungjee Kim, Joseph B. Tracy and Moungi G. Bawendi*
}

\section{Synthesis and ligand-exchange of Phosphine oxide polymer}

Synthesis: This synthesis should be conducted in a glove box. Degassed 7.75 $\mathrm{g}(12.92 \mathrm{mmol})$ poly(ethylene glycol)(Mn:600, Aldrich) is dissolved in $20.0 \mathrm{~g}$ of DMF for $1 \mathrm{hr}$ and then $1.0 \mathrm{~g}(4.31 \mathrm{mmol})$ 1,2-Bis(dichlorophosphino)ethane (Strem, 97\%) is added dropwise very slowly while the solution is vigorously stirred. The reaction solution is stirred at room temperature for one day after the addition. $2.38 \mathrm{~g}(17.24 \mathrm{mmol})$ $\mathrm{K}_{2} \mathrm{CO}_{3}$ and $10 \mathrm{ml} \mathrm{MeOH}$ are then added and stirred vigorously. The solution is stirred for several days until the $\mathrm{pH}$ reaches 7 to 8 . The solution is centrifuged and the precipitate is removed. The solvent is removed at a reduced pressure and the remaining solid is dissolved in $50 \mathrm{ml} \mathrm{CH}_{2} \mathrm{Cl}_{2}$. This last solution is then centrifuged and the precipitate is removed, leaving the product in the solution.

Ligand-exchange: Gold nanoparticles are precipitated using methanol and dispersed in $\mathrm{CH}_{2} \mathrm{Cl}_{2} .10 \mathrm{ml}$ of $\mathrm{CH}_{2} \mathrm{Cl}_{2}$ solution which contains the phosphine oxide polymer is mixed with $0.2 \mathrm{ml}$ of the nanoparticle solution (about $0.25 \mu \mathrm{M}$ ) for $1 \mathrm{~h}$ (an excess amount of polymer). The solvent is removed at a reduced pressure at room temperature and maintained at $100{ }^{\circ} \mathrm{C}$ for $1 \mathrm{~h}$ and then cooled to room temperature. De-ionized water is added and the solution is sonicated for $5 \mathrm{~min}$ and then filtered using a $0.1 \mu \mathrm{m}$ disposable filter. 